\section{OPEN ACCESS}

Edited by:

Bo Gao,

Affiliated Hospital of Guizhou Medical

University, China

Reviewed by:

Jiang He,

University of Virginia, United States

Xiu Juan Li,

Tai'an City Central Hospital, China

${ }^{*}$ Correspondence:

Steven P. Rowe

srowe8@jhmi.edu

Constantin Lapa

lapa_c@ukw.de

†These authors have contributed equally to this work

Specialty section:

This article was submitted to

Cancer Imaging and Image-directed Interventions,

a section of the journal

Frontiers in Oncology

Received: 28 April 2019

Accepted: 30 July 2019

Published: 14 August 2019

Citation:

Werner RA, Kircher S, Higuchi T, Kircher M, Schirbel A, Wester H-J, Buck AK, Pomper MG, Rowe SP and

Lapa C (2019) CXCR4-Directed Imaging in Solid Tumors. Front. Oncol. 9:770

doi: 10.3389/fonc.2019.00770

\title{
CXCR4-Directed Imaging in Solid Tumors
}

\author{
Rudolf A. Werner ${ }^{1,2,3}$, Stefan Kircher ${ }^{4}$, Takahiro Higuchi ${ }^{1,2,5}$, Malte Kircher $^{1,2}$, \\ Andreas Schirbel ${ }^{1}$, Hans-Jürgen Wester ${ }^{6}$, Andreas K. Buck ${ }^{1,2}$, Martin G. Pomper ${ }^{7,8}$, \\ Steven P. Rowe ${ }^{7,8 * t}$ and Constantin Lapa ${ }^{1,2 * t}$
}

\begin{abstract}
${ }^{1}$ Department of Nuclear Medicine, University of Wuerzburg, Wuerzburg, Germany, ${ }^{2}$ Comprehensive Heart Failure Center, University of Wuerzburg, Wuerzburg, Germany, ${ }^{3}$ Department of Nuclear Medicine, Hanover Medical School, Hanover, Germany, ${ }^{4}$ Institute for Pathology, University of Wuerzburg, Wuerzburg, Germany, ${ }^{5}$ Graduate School of Medicine, Dentistry and Pharmaceutical Sciences, Okayama University, Okayama, Japan, ${ }^{6}$ Pharmaceutical Radiochemistry, Technische Universität München, Munich, Germany, ${ }^{7}$ Division of Nuclear Medicine and Molecular Imaging, The Russell H. Morgan Department of Radiology and Radiological Science, Johns Hopkins University School of Medicine, Baltimore, MD, United States, ${ }^{8}$ Department of Urology, The James Buchanan Brady Urological Institute, Johns Hopkins University School of Medicine, Baltimore, MD, United States
\end{abstract}

Despite histological evidence in various solid tumor entities, available experience with CXCR4-directed diagnostics and endoradiotherapy mainly focuses on hematologic diseases. With the goal of expanding the application of CXCR4 theranostics to solid tumors, we aimed to elucidate the feasibility of CXCR4-targeted imaging in a variety of such neoplasms.

Methods: Nineteen patients with newly diagnosed, treatment-naïve solid tumors including pancreatic adenocarcinoma or neuroendocrine tumor, cholangiocarcinoma, hepatocellular carcinoma, renal cell carcinoma, ovarian cancer, and prostate cancer underwent $\left[{ }^{68} \mathrm{Ga}\right]$ Pentixafor PET/CT. CXCR4-mediated uptake was assessed both visually and semi-quantitatively by evaluation of maximum standardized uptake values $\left(S U V_{\max }\right)$ of both primary tumors and metastases. With physiologic liver uptake as reference, tumor-to-background ratios (TBR) were calculated. $\left[{ }^{68} \mathrm{Ga}\right]$ Pentixafor findings were further compared to immunohistochemistry and $\left[{ }^{18} \mathrm{~F}\right] \mathrm{FDG}$ PET/CT.

Results: On [ $\left.{ }^{68} \mathrm{Ga}\right]$ Pentixafor PET/CT, 10/19 (52.6\%) primary tumors were visually detectable with a median SUV $V_{\max }$ of 5.4 (range, 1.7-16.0) and a median TBR of 2.6 (range, 0.8-7.4), respectively. The highest level of radiotracer uptake was identified in a patient with cholangiocarcinoma $\left(S U V_{\max }, 16.0\right.$; TBR, 7.4). The relatively low uptake on $\left[{ }^{68} \mathrm{Ga}\right]$ Pentixafor was also noted in metastases, exhibiting a median SUV max of 4.5 (range, 2.3-8.8; TBR, 1.7; range, 1.0-4.1). A good correlation between uptake on $\left[{ }^{68} \mathrm{Ga}\right]$ Pentixafor and histological derived CXCR4 expression was noted $(R=0.62$, $P<0.05)$. In the 3 patients in whom $\left[{ }^{18} \mathrm{~F}\right.$ FDG PET/CT was available, $\left[{ }^{68} \mathrm{Ga}\right]$ Pentixafor exhibited lower uptake in all lesions.

Conclusions: In this cohort of newly diagnosed, treatment-naive patients with solid malignancies, CXCR4 expression as detected by [ $\left.{ }^{68} \mathrm{Ga}\right]$ Pentixafor-PET/CT and immunohistochemistry was rather moderate. Thus, CXCR4-directed imaging may not play a major role in the management of solid tumors in the majority of patients.

Keywords: CXCR4, $\left[{ }^{68} \mathrm{Ga}\right]$ Pentixafor, theranostics, solid tumors, chemokine receptor 


\section{INTRODUCTION}

C-X-C motif chemokine receptor 4 (CXCR4) is overexpressed in more than 20 tumor types and plays a crucial role in tumor growth, tumor invasiveness, cancer cell-microenvironment interaction, and metastasis $(1,2)$. Notably, the presence of CXCR4 has been linked to unfavorable outcomes in multiple different tumor entities, including hematologic malignancies, breast cancer, renal cell carcinoma, gynecologic malignancies, pancreatic adenocarcinoma, and hepatocellular carcinoma (3).

$\left[{ }^{68} \mathrm{Ga}\right]$ Pentixafor is a radiolabelled CXCR4 ligand that allows for sensitive and high-contrast visualization of the presence of the receptor in vivo $(4,5)$. Its use for non-invasive wholebody positron emission tomography (PET) imaging has been demonstrated in multiple (mainly hematologic) malignancies and also inflammatory disease conditions (6-14). Additionally, ${ }^{90} \mathrm{Y}$ - or ${ }^{177} \mathrm{Lu}$-labeled Pentixather (15), the therapeutic partner of $\left[{ }^{68} \mathrm{Ga}\right]$ Pentixafor, has successfully been introduced for the treatment of hematologic neoplasias such as multiple myeloma, diffuse large B cell lymphoma, and acute myeloid leukemia (16-20).

In solid malignancies, pilot studies have hinted at a role for CXCR4-directed imaging in various selected diseases, such as small cell lung cancer, esophageal adenocarcinoma, and poorly differentiated neuroendocrine neoplasms (21-23). Of note, Blümel et al. reported on the use of $\left[{ }^{68} \mathrm{Ga}\right]$ Pentixafor in patients diagnosed with adrenocortical cancer, with $70 \%$ of the subjects being potentially suitable for a treatment with $\left[{ }^{177} \mathrm{Lu}\right] /\left[{ }^{90} \mathrm{Y}\right]$ Pentixather (24).

On the other hand, Vag et al. could not detect relevant $\left[{ }^{68} \mathrm{Ga}\right]$ Pentixafor uptake in a heterogenous subset of different solid cancers, including non-small cell lung cancer, malignant melanoma, sarcoma, cancer of unknown primary (CUP), or breast cancer (25). Our group reported on rather discouraging results in a small cohort of patients with malignant pleural mesothelioma (26).

Thus, given these contradictory findings among different solid tumor entities, we aimed to broaden the experience of CXCR4-targeted PET imaging in solid cancers by investigating a subset of different tumors, including cholangiocarcinoma (CCC), hepatocellular carcinoma (HCC), pancreatic adenocarcinoma or neuroendocrine tumor, and ovarian cancer.

\section{MATERIALS AND METHODS}

$\left[{ }^{68} \mathrm{Ga}\right]$ Pentixafor was administered on a compassionate use basis in compliance with $\$ 37$ of the Declaration of Helsinki and The German Medicinal Products Act, AMG \$13.2b. All patients underwent imaging for clinical purposes and gave written and informed consent to the diagnostic procedures. The local institutional review board waived the requirement for additional approval because of the retrospective character of this study.

\section{Patients}

Between September, 2014 and August, 2015, 19 patients (11 males, 8 females; aged $71 \pm 7$ years; range, 6081 y) with newly diagnosed, treatment-naive solid tumors underwent $\left[{ }^{68} \mathrm{Ga}\right]$ Pentixafor-PET/computed tomography (CT) for assessment of CXCR4 expression. In 3/19 (15.8\%) subjects, additional $\left[{ }^{18} \mathrm{~F}\right] \mathrm{FDG}$ PET/CT was also performed for staging purposes within 2 weeks after $\left[{ }^{68} \mathrm{Ga}\right]$ Pentixafor-PET (interval between both scans, median 8 days; range, 1-12 d).

Following imaging, $17 / 19(89.5 \%)$ subjects underwent either tumor biopsy $(8 / 17,47.1 \%)$ or surgery $(n=9 / 17$, $52.9 \%$ ) after a median of 4.5 days (range, $1-55 \mathrm{~d}$ ). Table 1 gives an overview of the clinical information for this patient cohort.

\section{Synthesis of $\left[{ }^{68} \mathrm{Ga}\right]$ Pentixafor}

${ }^{68} \mathrm{Ga}$ ]Pentixafor was synthesized as previously described using a fully GMP compliant automated synthesizer (GRP, Scintomics, Fürstenfeldbruck, Germany) (27).

\section{PET Imaging}

All PET/CT scans were performed on a dedicated PET/CT scanner (Siemens Biograph mCT 64; Siemens Healthineers, Erlangen, Germany). Before acquisition of $\left[{ }^{18} \mathrm{~F}\right] \mathrm{FDG}$ PET, patients fasted for at least $6 \mathrm{~h}$ and blood glucose levels were $<160 \mathrm{mg} / \mathrm{dl}$. Prior to $\left[{ }^{68} \mathrm{Ga}\right]$ Pentixafor, patients did not fast. Imaging was performed $60 \mathrm{~min}$ after administration of 64-166 $\mathrm{MBq}$ (median, $145 \mathrm{MBq})$ of $\left[{ }^{68} \mathrm{Ga}\right]$ Pentixafor and $297(n=1)$ or $301(n=2) \mathrm{MBq}$ of $\left[{ }^{18} \mathrm{~F}\right] \mathrm{FDG}$, respectively. Spiral CT with (dose modulation with a quality reference of $210 \mathrm{mAs}$ ) or without $(80 \mathrm{mAs})$ intravenous contrast $(120 \mathrm{kV}, 512 \times 512$ matrix, $5 \mathrm{~mm}$ slice thickness) including a field of view from the base of the skull to the proximal thighs was acquired. Consecutively, PET emission data were acquired in three-dimensional mode with a $200 \times 200$ matrix with $2-3$ min emission time per bed position. After decay and scatter correction, PET data were reconstructed iteratively with attenuation correction using the algorithm implemented by the manufacturer (Siemens Esoft, Siemens Healthineers, Erlangen, Germany).

\section{Image Analysis}

All PET/CT studies were visually assessed by two experienced nuclear medicine physicians (RAW and CL). Lesions were rated as visually detectable if they could be identified by both reviewers on the PET images in a consensus setting.

For derivation of maximum standardized uptake values $\left(\mathrm{SUV}_{\max }\right)$ of both primary tumors (all patients) and metastatic disease (if present, in $n=7 / 19,36.8 \%$ ), 3-dimensional volumes of interest (VOI) were drawn around the respective lesions. If patients displayed more than 5 metastases (all histologically proven or verified by imaging follow-up), the five lesions with the highest uptake were selected. For calculation of tumor-tobackground ratios (TBR), VOIs with a diameter of $3 \mathrm{~cm}$ were placed in normal liver parenchyma and mean SUV were noted. The radiotracer concentration in the VOI was normalized to the injected dose per kilogram of patient's body weight to derive the SUVs (22).

For $\left[{ }^{18} \mathrm{~F}\right] \mathrm{FDG}-\mathrm{PET} / \mathrm{CT}$, an analogous procedure was carried out. 
TABLE 1 | Overview of included subjects.

\begin{tabular}{|c|c|c|c|c|c|c|c|c|c|c|c|}
\hline \multirow[t]{2}{*}{ Patient no. } & \multirow[t]{2}{*}{$\begin{array}{l}\text { Tumor } \\
\text { entity }\end{array}$} & \multirow[t]{2}{*}{ Grading* } & \multirow[t]{2}{*}{ TNM $^{*}$} & \multirow{2}{*}{$\begin{array}{l}\text { Visually } \\
\text { detectable } \\
\text { lesions on PET }\end{array}$} & \multicolumn{3}{|c|}{ Primary on $\left[{ }^{68} \mathrm{Ga}\right]$ Pentixafor PET } & \multicolumn{3}{|c|}{$\begin{array}{c}\text { Metastases on }\left[{ }^{68} \mathrm{Ga}\right] \text { Pentixafor } \\
\text { PET }\end{array}$} & \multirow[t]{2}{*}{ IRS } \\
\hline & & & & & SUV $_{\max }$ & TBR & VD & SUV $_{\max }$ & TBR & VD & \\
\hline 1 & $\mathrm{CCC}$ & G2 & - & 1 & 4.65 & 1.68 & 0 & - & - & $0 / 1$ & 0 \\
\hline 2 & RCC & G2 & pT1b pNX Mx & 1 & 1.88 & 0.88 & 0 & - & - & $0 / 1$ & 1 \\
\hline 3 & $\begin{array}{l}\text { Pancreas } \\
\text { (NET) }\end{array}$ & G1 & - & 3 & 5.77 & 2.68 & 1 & 2.92 & 1.36 & $2 / 3$ & 9 \\
\hline 5 & PDAC & - & pT3 Nx Mx & 1 & 7.13 & 2.57 & 0 & - & - & $0 / 1$ & 4 \\
\hline 6 & CUP & - & - & 3 & - & - & 0 & 2.33 & 0.96 & $3 / 3$ & 0 \\
\hline 7 & $\mathrm{CCC}$ & - & Tx Nx M1 & 3 & 16 & 7.41 & 1 & 8.83 & 4.09 & $2 / 3$ & 12 \\
\hline 8 & $\mathrm{HCC}$ & - & - & 0 & 4.39 & 2.71 & 0 & - & - & - & - \\
\hline 11 & PDAC & - & - & 0 & 7.58 & 3.72 & 1 & - & - & - & 9 \\
\hline 12 & $\mathrm{CCC}$ & G3 & pT1 pNx Mx & 2 & 12.09 & 5.02 & 1 & 6.67 & 2.77 & $1 / 2$ & 2 \\
\hline 13 & $\mathrm{HCC}$ & G3 & pT2 pNx Mx & 1 & 4.97 & 3.88 & 1 & - & - & $0 / 1$ & 0 \\
\hline 14 & PDAC & - & - & 1 & 8.22 & 2.07 & 1 & - & - & $0 / 1$ & 6 \\
\hline 15 & $\begin{array}{l}\text { Ovarian } \\
\text { (granulosa } \\
\text { cell tumor) }\end{array}$ & - & pT1a pNx Mx & 1 & 2.69 & 1.48 & 0 & - & - & $0 / 1$ & 0 \\
\hline 16 & PDAC & G2 & pT2 pN1 Mx & $>5$ & 9.22 & 3.35 & 1 & 4.45 & 1.62 & $1 / 5$ & 2 \\
\hline 17 & $\mathrm{HCC}$ & G3 & pT1 pNO Mx & 0 & 3.74 & 1.33 & 0 & - & - & $0 / 1$ & 0 \\
\hline 18 & $\begin{array}{l}\text { Ovarian } \\
\text { (high-grade } \\
\text { serous) }\end{array}$ & G3 & рТЗc Nx Mx & $>5$ & 2.26 & 1.06 & 0 & - & - & $0 / 5$ & 3 \\
\hline
\end{tabular}

PET, positron emission tomography; IRS, immunoreactive score; SUV max, maximum standardized uptake value; TBR, tumor to background ratio; VD, visual detectability; CCC,

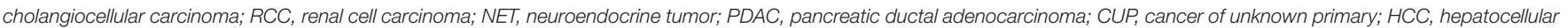
carcinoma. All patients underwent $\left[{ }^{68}\right.$ Ga]Pentixafor PET/CT, while in 3/19 subjects, additional $\left[{ }^{18}\right.$ F]FDG PET/CT was performed. ${ }^{*}$ prior to CXCR4-directed imaging.

\section{Histological Tumor Characterization}

Immunohistochemistry was performed on $10 \%$ formalin fixed paraffin embedded tissue sections $(3 \mu \mathrm{m})$ and scored as previously described (28). CXCR4-immunohistochemistry was conducted using an anti-CXCR4 rabbit polyclonal antibody (ab2074; Abcam, Cambridge, United Kingdom) followed by detection with the DAKO en vision system according to the manufacturer's protocol. All immunostained sections were counterstained for $3 \mathrm{~min}$ with hematoxylin. The analysis of the stained sections was done semi-quantitatively by lightmicroscopy according to the immunoreactive score (IRS) by Remmele and Stegner (29). The percentage of CXCR4-positive cells was scored as follows: 0 (no positive cells), $1(<10 \%$ positive cells), 2 ( $10-50 \%$ positive cells), 3 ( $>50-80 \%$ positive cells), and 4 ( $>80 \%$ positive cells). Additionally, the intensity of staining was graded: 0 (no color reaction), 1 (mild reaction), 2 (moderate reaction), 3 (intense reaction). Multiplication of both scores for a given sample yields the IRS classification: 0-1 (negative), 23 (mild), 4-8 (moderate), 9-12 (strongly positive). For a more detailed description please refer to Werner et al. (22). IRS were correlated with imaging findings.

\section{Statistical Analysis}

Descriptive statistics were predominantly utilized. All results are displayed as mean $\pm \mathrm{SD}$ or as median + range where appropriate. The two-tailed paired Student's $t$-test was used to check for a correlation between $\left[{ }^{68} \mathrm{Ga}\right]$ Pentixafor $\mathrm{SUV}_{\max }$ and histologic CXCR4 expression. A $P$-value of $<0.05$ was considered to be statistically significant.

\section{RESULTS}

\section{Clinical Findings}

All patients presented with newly diagnosed, treatment-naïve solid tumors. The following histologic entities were represented in the cohort: pancreatic ductal adenocarcinoma $(n=4)$, pancreatic neuroendocrine tumor $(n=2$, initially suspected as adenocarcinoma), CCC $(n=4)$, HCC $(n=3)$, and ovarian cancer ( $n=3$, one low- and one high-grade serous carcinoma as well as one granulosa cell tumor of the ovary, respectively). The remaining three subjects had, renal cell carcinoma (RCC), prostate cancer, and CUP, respectively. Evidence of metastases was detected in $7 / 19(36.8 \%)$ patients. 
Patient details are provided in Table 1.

\section{Imaging Results of [ $\left.{ }^{68} \mathrm{Ga}\right]$ Pentixafor PET/CT}

On a visual basis, 10/19 (52.6\%) primary tumors and 14/49 (28.6\%) metastases were detectable. In semi-quantitative analysis, the median $S_{U V}$ max of the primary was 5.4 (range, 1.7-16.0) with a median TBR of 2.6 (range, 0.8-7.4). The highest $\mathrm{SUV}_{\max }$ were identified in patients suffering from CCC (\#7, SUV $\max , 16.0$; $\# 12$, $\mathrm{SUV}_{\max }, 12.1$; Table 1).

Metastases exhibited a median $\mathrm{SUV}_{\max }$ of 4.5 (range, 2.3-8.8) with a TBR of 1.7 (range, 1.0-4.1).

\section{Comparison of $\left[{ }^{68} \mathrm{Ga}\right]$ Pentixafor PET/CT With $\left[{ }^{18}\right.$ F]FDG PET/CT}

In $3 / 19(15.8 \%)$ patients (\#3, \#8, and \#10), an additional $\left[{ }^{18} \mathrm{~F}\right] \mathrm{FDG}$ PET/CT scan was conducted. The primary tumor was identified in all subjects, while it was not visualized in $2 / 3$ by $\left[{ }^{68} \mathrm{Ga}\right]$ Pentixafor $(\# 8$ and $\# 10)$. In semi-quantitative assessment, both $\mathrm{SUV}_{\max }$ and TBR were higher than on CXCR4-directed imaging: Median SUV $\mathrm{Sux}_{\max }$ of the primary was $14.3\left(14.3,18.0,9.0 ;\left[{ }^{68} \mathrm{Ga}\right]\right.$ Pentixafor, $4.4 ; 5.8,4.4,1.7$, respectively) with a median TBR of 4.8 (range, 2.9-6.7; $\left[{ }^{68} \mathrm{Ga}\right]$ Pentixafor, 2.7; 2.7, 2.7, 0.8 , respectively).

$\left[{ }^{18} \mathrm{~F}\right]$ FDG PET/CT detected metastases in $2 / 3$ (\#3 and \#8) patients with a median $\mathrm{SUV}_{\max }$ of 13.3 (range, 11.5-16.6) and a median TBR of 4.7 (range, 3.9-5.6) whereas [ ${ }^{68} \mathrm{Ga}$ ]Pentixafor visualized only 2 metastases in patient \#3 (SUV $\max , 3.9$ and 2.0 , respectively).

\section{Immunohistochemical Assessment}

A total of 17 samples could be investigated in a pathological assessment. 5/17 samples (29.4\%) were rated as negative, 6/17 (35.4\%) as "weakly" positive (IRS score 1-3), 3/17 (17.6\%) as "moderately" positive (IRS scores 4-8), and $3 / 17$ (17.6\%) as "strongly" positive (IRS scores 9-12) (Table 1). Notably, both membranous as well as intra-cytoplasmatic staining for CXCR4 was confirmed.

In $16 / 17$ (94.1\%), imaging results ( $\mathrm{SUV}_{\max }$ of the primary) could be compared to immunohistological CXCR4 staining, while in $1 / 17(5.9 \%)$ a $\mathrm{SUV}_{\max }$ could not be derived as the primary could not be identified (\#6, suffering from CUP). A significant correlation between IRS and $\left[{ }^{68} \mathrm{Ga}\right]$ Pentixafor $\mathrm{SUV}_{\max }$ of the primary among all tumor entities was detected ( $\mathrm{R}=0.62, P<0.05$, Figure 1$)$. Figure 2 shows concordant cases of immunohistochemistry and non-invasive imaging in patients suffering from CCC (patient \#7) and HCC (patient \#17), respectively. Figure 3 demonstrates CXCR4-directed imaging in further selected tumor entities which (with the exception of patient \#9 suffering from low-grade ovarian carcinoma) primarily demonstrated moderate to no uptake on CXCR4directed imaging.

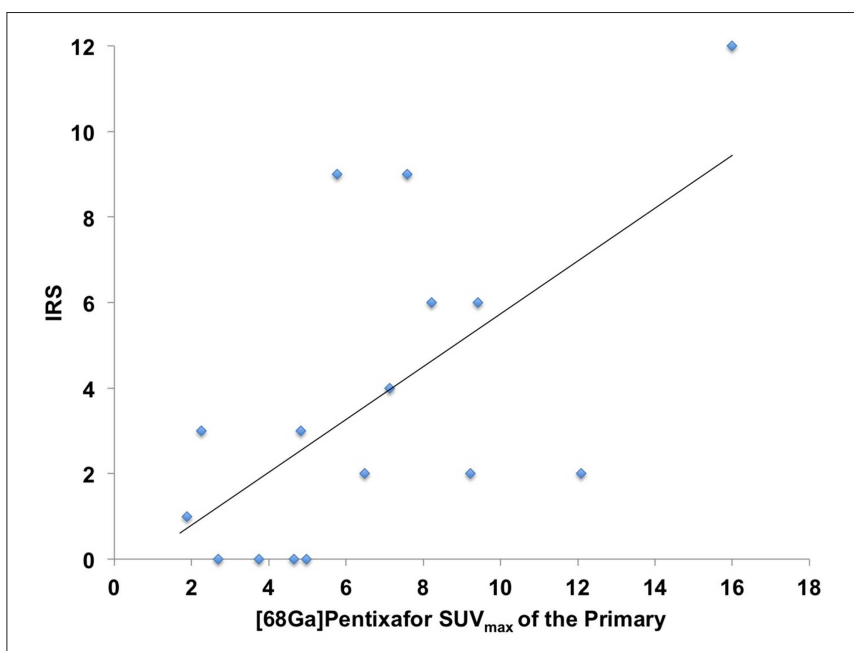

FIGURE 1 | Correlation between immunoreactive score (IRS) vs. $\left[{ }^{68} \mathrm{Ga}\right]$ Pentixafor $S U V_{\max }$ of the primary among all tumor entities available for analysis $R=0.62$.

\section{DISCUSSION}

An extensive body of literature has demonstrated that overexpression of CXCR4 is linked with increased aggressiveness and worse prognosis in solid cancers. Thus, this chemokine receptor is an interesting target in oncology and several therapeutic antagonists have been developed $(30,31)$. A recent phase I trial in women with advanced HER-2 negative metastatic breast cancer investigated a combination regimen of balixafortide (a peptidic CXCR4 antagonist) and eribulin and demonstrated favorable safety and tolerability as well as promising anti-tumor activity (32). Additionally, a first experience with chemokine receptor-directed radioligand therapy in heavily pre-treated hematologic disease has been reported (17-19).

As an important pre-requisite to CXCR4 directed therapy, $\left[{ }^{68} \mathrm{Ga}\right]$ Pentixafor PET/CT enables the non-invasive evaluation of receptor expression of all tumor lesions. Marked inter- and intraindividual differences in CXCR4 expression have been noted (33). Further, the receptor presentation on the tumor cell surface seems to be highly dynamic and influenced by a variety of factors including previous therapy (34).

In this study, we aimed to expand the experience with noninvasive imaging of CXCR4 in solid cancers. Previous reports had hinted at a potential role of chemokine-directed imaging in selected entities such as small cell lung cancer, adrenocortical carcinoma, or glioblastoma $(21,24,35)$, while another study by Vag et al. questioned its suitability in other tumors including sarcoma, pancreatic cancer, and breast cancer (25). In the present analysis, additional solid cancers in which CXCR4 expression had been linked to metastasis and inferior outcomes such as renal cell cancer (36), ovarian cancer (37), and CCC (38) were investigated. All patients presented with newly diagnosed, treatment-naïve disease. To exclude potential influence of concomitant therapy on receptor surface expression, biopsies, and/or surgery were performed shortly after PET imaging and prior to treatment 

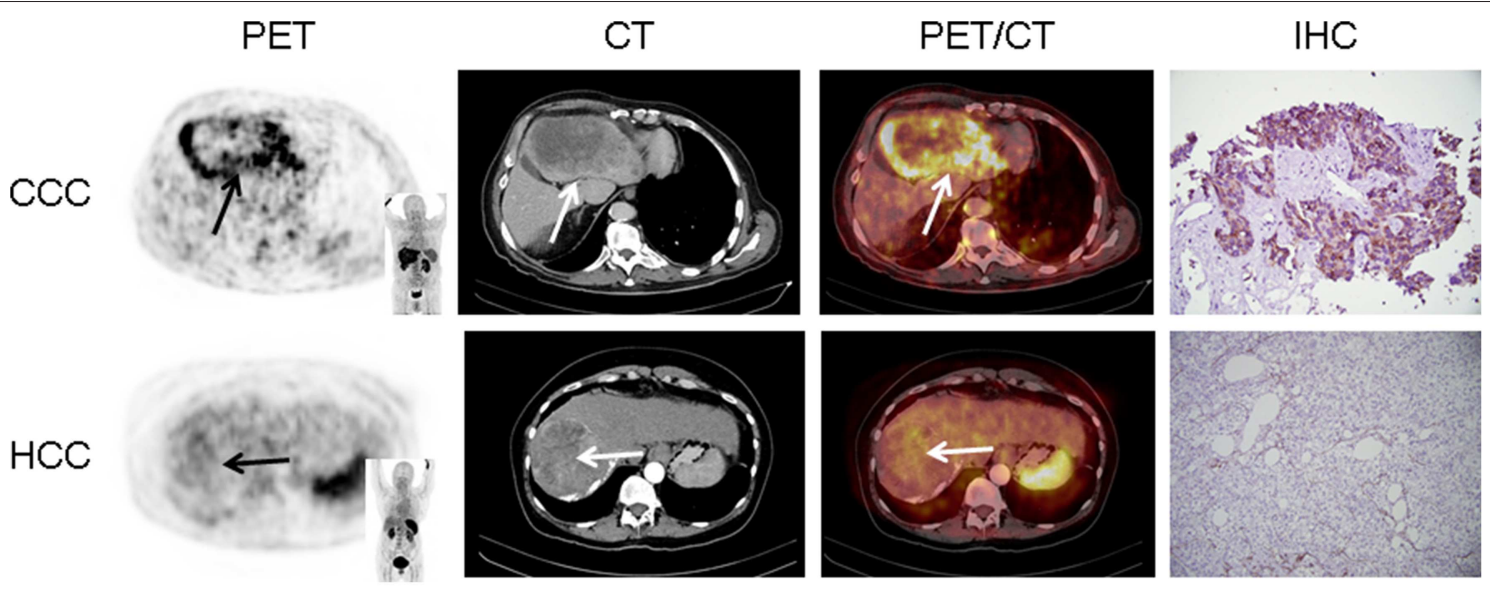

FIGURE 2 | Concordance of immunohistochemistry (IHC) and non-invasive CXCR4-directed positron emission tomography (PET) imaging in patients suffering from cholangiocellular carcinoma (CCC, upper row, patient \#7) and hepatocellular carcinoma (HCC, lower row, patient \#17). Upper row (patient \#7): Display of transaxial PET (left), computed tomography (CT, second panel) and fused PET/CT (third panel) images of a left liver lesion. The lesion demonstrates high CXCR4 expression, which could be confirmed in the surgical specimen after tumor resection (IHC, fourth panel). The immunoreactive score (IRS) was 12 (Table 1). Lower row (patient \#17): Display of transaxial PET (left), CT (second panel) and fused PET/CT (third panel) images of the primary. The lesions demonstrates no CXCR4 expression on PET. The patient presented with negative IHC for CXCR4 derived from a surgical specimen (IRS, 0, Table 1). Magnification of IHC: $\times 400$.

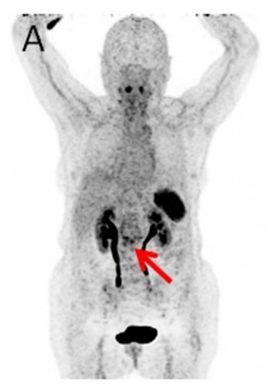

PDAC

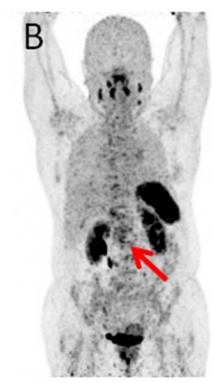

PNET

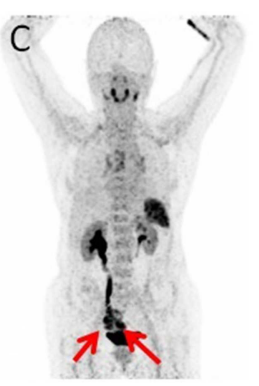

Ovarian Ca

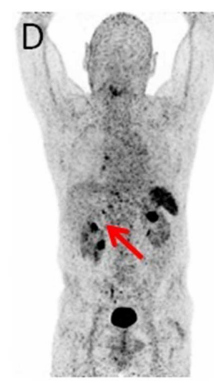

RCC

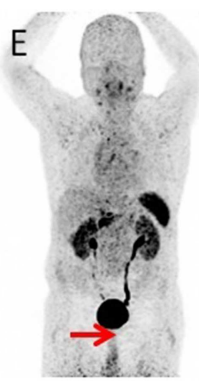

$\mathrm{PCa}$

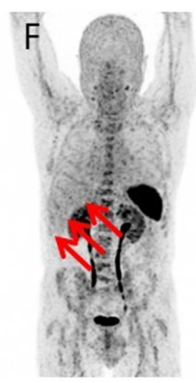

CUP

FIGURE 3 | Maximum intensity projections of CXCR4-directed positron emission tomography of other selected tumor entities, primarily demonstrating moderate to no uptake on CXCR4-directed imaging (arrows). Pancreatic ductal adenocarcinoma [PDCA; (A)], pancreatic neuroendocrine tumor [PNET; (B)], ovarian cancer (C), renal cell carcinoma [RCC; (D)], prostate cancer [PCA; (E)], and cancer of unknown primary (CUP) with multiple liver metastases (F). Only the tumor masses of the patient with low-grade ovarian carcinoma (patient \#9) display relevant CXCR4 expression.

initiation. However, only weak to moderate $\left[{ }^{68} \mathrm{Ga}\right]$ Pentixafor uptake was recorded in the vast majority of patients and almost $80 \%$ of lesions could not be visually detected. In addition, only two patients exhibited primary tumor $\mathrm{SUV}_{\max }>10$. Interestingly, both patients suffered from CCC (\#7, Figure 2 and $\# 12$ ). These findings were paralleled by immunohistochemistry that also identified relevant CXCR4 expression in few tumor specimens and correlated well with non-invasive imaging results ( $R=0.62$, Figure 1$)$.

Taken together, the current findings indicate that $\left[{ }^{68} \mathrm{Ga}\right]$ Pentixafor is unlikely to play a major role in staging and re-staging of most solid tumors, in particular when compared to $\left[{ }^{18} \mathrm{~F}\right] \mathrm{FDG}$. Given the physiologic expression of CXCR4 on hematopoietic stem cells and thus the need for subsequent stem cell support $(17,18)$, endoradiotherapy with radiolabelled Pentixather might also be reserved to very selected cases.

Future efforts for potential applications of CXCR4-directed imaging might focus on the characterization of intra-/interlesional heterogeneity by performing dual-radiotracer studies (in conjunction with $\left[{ }^{18} \mathrm{~F}\right] \mathrm{FDG}$ ) to visualize different levels of tumor de-differentiation and predict lesions with prognostic relevance. For example, CXCR4-directed PET/CT might help to visualize receptor positive cancer stem cells (and their niche) which are considered to be especially resistant to radiation or chemotherapy $(1,39)$.

Several limitations of the present study have to be considered. It is retrospective and the number of patients is rather small. Further research including a higher number of subjects is 
definitely warranted to confirm the preliminary findings of the present feasibility study. Histologic validation of imaging results was not available in all cases. Additionally, a variety of different tumor entities were included. However, all patients presented with newly diagnosed disease and were treatment-naïve at the time of imaging. Moreover, in only 3 patients, an additional $\left[{ }^{18} \mathrm{~F}\right]$ FDG PET/CT has been conducted and future studies should evaluate potential tumor heterogeneity in a higher number of subjects. Although the value of $\left[{ }^{68} \mathrm{Ga}\right]$ Pentixafor PET/CT has been investigated before, our small series adds first experience with other tumor entities such as ovarian cancer and renal cell carcinoma, along with histopathologic proof in the majority of the cases.

\section{CONCLUSIONS}

In this cohort of various treatment-naïve solid malignancies, CXCR4 expression as detected by $\left[{ }^{68} \mathrm{Ga}\right]$ Pentixafor-PET/CT and immunohistochemistry was rather moderate. Thus, CXCR4directed imaging may not play a major role in the management of the majority of solid cancer patients.

\section{DATA AVAILABILITY}

The raw data supporting the conclusions of this manuscript will be made available by the authors, without undue reservation, to any qualified researcher.

\section{REFERENCES}

1. Domanska UM, Kruizinga RC, Nagengast WB, Timmer-Bosscha H, Huls G, de Vries EG, et al. A review on CXCR4/CXCL12 axis in oncology: no place to hide. Eur J Cancer. (2013) 49:219-30. doi: 10.1016/j.ejca.2012.05.005

2. Walenkamp AME, Lapa C, Herrmann K, Wester HJ. CXCR4 ligands: the next big hit? J Nucl Med. (2017) 58:77S-82S. doi: 10.2967/jnumed.116.1 86874

3. Zhao H, Guo L, Zhao H, Zhao J, Weng H, Zhao B. CXCR4 over-expression and survival in cancer: a system review and meta-analysis. Oncotarget. (2015) 6:5022-40. doi: 10.18632/oncotarget.3217

4. Demmer O, Gourni E, Schumacher U, Kessler H, Wester HJ. PET imaging of CXCR4 receptors in cancer by a new optimized ligand. ChemMedChem. (2011) 6:1789-91. doi: 10.1002/cmdc.201100320

5. Gourni E, Demmer O, Schottelius M, D'Alessandria C, Schulz S, Dijkgraaf I, et al. PET of CXCR4 expression by a (68)Ga-labeled highly specific targeted contrast agent. J Nucl Med. (2011) 52:180310. doi: 10.2967/jnumed.111.098798

6. Wester HJ, Keller U, Schottelius M, Beer A, Philipp-Abbrederis K, Hoffmann F, et al. Disclosing the CXCR4 expression in lymphoproliferative diseases by targeted molecular imaging. Theranostics. (2015) 5:61830. doi: 10.7150/thno.11251

7. Philipp-Abbrederis K, Herrmann K, Knop S, Schottelius M, Eiber $\mathrm{M}$, Luckerath $\mathrm{K}$, et al. In vivo molecular imaging of chemokine receptor CXCR4 expression in patients with advanced multiple myeloma. EMBO Mol Med. (2015) 7:477-87. doi: 10.15252/emmm.2014 04698

8. Kircher M, Herhaus P, Schottelius M, Buck AK, Werner RA, Wester HJ, et al. CXCR4-directed theranostics in oncology and inflammation. Ann Nucl Med. (2018) 32:503-11. doi: 10.1007/s12149-018-1290-8

9. Reiter T, Kircher M, Schirbel A, Werner RA, Kropf S, Ertl G, et al. Imaging of C-X-C motif chemokine receptor CXCR4 expression after myocardial

\section{ETHICS STATEMENT}

The local institutional review board of University Würzburg waived the requirement for additional approval because of the retrospective character of this study. All subjects gave written informed consent in accordance with the Declaration of Helsinki.

\section{AUTHOR CONTRIBUTIONS}

RW, SK, CL, TH, MP, and SR designed the study, wrote the manuscript, and researched data. $\mathrm{MK}, \mathrm{AS}, \mathrm{H}-\mathrm{JW}$, and $\mathrm{AB}$ performed analysis. All authors aided in drafting the manuscript and revised it critically for important intellectual content. All authors read and approved the final manuscript.

\section{FUNDING}

This work was supported by the Competence Network of Heart Failure funded by the Integrated Research and Treatment Center (IFB) of the Federal Ministry of Education and Research (BMBF) and German Research Council (DFG grant HI 1789/33). This publication was funded by the German Research Foundation (DFG) and the University of Wuerzburg in the funding programme Open Access Publishing. This work was supported by Grants-in-Aid for Scientific Research (Kakenhi, 15K21774) from the Japan Society for the Promotion of Science (JSPS).

infarction with $[(68) \mathrm{Ga}]$ Pentixafor-PET/CT in correlation with cardiac MRI. JACC Cardiovasc Imaging. (2018) 11:1541-3. doi: 10.1016/j.jcmg.2018. 01.001

10. Lapa C, Reiter T, Werner RA, Ertl G, Wester HJ, Buck AK, et al. [(68)Ga]Pentixafor-PET/CT for imaging of chemokine receptor 4 expression after myocardial infarction. JACC Cardiovasc Imaging. (2015) 8:14668. doi: $10.1016 / j . j c m g .2015 .09 .007$

11. Derlin T, Sedding DG, Dutzmann J, Haghikia A, Konig T, Napp LC, et al. Imaging of chemokine receptor CXCR4 expression in culprit and nonculprit coronary atherosclerotic plaque using motion-corrected [(68)Ga]pentixafor PET/CT. Eur J Nucl Med Mol Imaging. (2018) 45:193444. doi: 10.1007/s00259-018-4076-2

12. Weiberg D, Thackeray JT, Daum G, Sohns JM, Kropf S, Wester HJ, et al. Clinical molecular imaging of chemokine receptor CXCR4 expression in atherosclerotic plaque using (68)Ga-Pentixafor PET: correlation with cardiovascular risk factors and calcified plaque burden. J Nucl Med. (2018) 59:266-72. doi: 10.2967/jnumed.117.196485

13. Thackeray JT, Derlin T, Haghikia A, Napp LC, Wang Y, Ross TL, et al. Molecular imaging of the chemokine receptor CXCR4 after acute myocardial infarction. JACC Cardiovasc Imaging. (2015) 8:141726. doi: 10.1016/j.jcmg.2015.09.008

14. Werner RA, Weich A, Schirbel A, Samnick S, Buck AK, Higuchi T, et al. Intraindividual tumor heterogeneity in NET - Further insight by C-X-C motif chemokine receptor 4-directed imaging. Eur J Nucl Med Mol Imaging. (2017) 44:553-4. doi: 10.1007/s00259-016-3566-3

15. Schottelius M, Osl T, Poschenrieder A, Hoffmann F, Beykan S, Hanscheid H, et al. [177Lu]pentixather: comprehensive preclinical characterization of a first CXCR4-directed endoradiotherapeutic agent. Theranostics. (2017) 7:235062. doi: 10.7150/thno.19119

16. Herrmann K, Schottelius M, Lapa C, Osl T, Poschenrieder A, Hanscheid H, et al. First-in-human experience of CXCR4-directed endoradiotherapy with 177Lu- and 90Y-labeled pentixather in advanced-stage multiple myeloma 
with extensive intra- and extramedullary disease. J Nucl Med. (2016) 57:24851. doi: 10.2967/jnumed.115.167361

17. Lapa C, Herrmann K, Schirbel A, Hanscheid H, Luckerath K, Schottelius $\mathrm{M}$, et al. CXCR4-directed endoradiotherapy induces high response rates in extramedullary relapsed multiple myeloma. Theranostics. (2017) 7:158997. doi: 10.7150/thno.19050

18. Lapa C, Hanscheid H, Kircher M, Schirbel A, Wunderlich G, Werner R, et al. Feasibility of CXCR4-directed radioligand therapy in advanced diffuse large B cell lymphoma. J Nucl Med. (2018) 60:60-4. doi: 10.2967/jnumed.118.210997

19. Habringer S, Lapa C, Herhaus P, Schottelius M, Istvanffy R, Steiger K, et al. Dual targeting of acute leukemia and supporting niche by CXCR4-directed theranostics. Theranostics. (2018) 8:369-83. doi: 10.7150/thno.21397

20. Maurer S, Herhaus P, Lippenmeyer R, Hanscheid H, Kircher M, Schirbel A, et al. Side effects of CXC-chemokine receptor 4 - directed endoradiotherapy with pentixather prior to hematopoietic stem cell transplantation. J Nucl Med. (2019). doi: 10.2967/jnumed.118.223420. [Epub ahead of print].

21. Lapa C, Luckerath K, Rudelius M, Schmid JS, Schoene A, Schirbel A, et al. [68Ga]Pentixafor-PET/CT for imaging of chemokine receptor 4 expression in small cell lung cancer - initial experience. Oncotarget. (2016) 7:928895. doi: 10.18632/oncotarget.7063

22. Werner RA, Weich A, Higuchi T, Schmid JS, Schirbel A, Lassmann M, et al. Imaging of chemokine receptor 4 expression in neuroendocrine tumors - a triple tracer comparative approach. Theranostics. (2017) 7:148998. doi: 10.7150/thno.18754

23. Fang HY, Munch NS, Schottelius M, Ingermann J, Liu H, Schauer M, et al. CXCR4 is a potential target for diagnostic PET/CT imaging in Barrett's dysplasia and esophageal adenocarcinoma. Clin Cancer Res. (2018) 24:104861. doi: 10.1158/1078-0432.CCR-17-1756

24. Bluemel C, Hahner S, Heinze B, Fassnacht M, Kroiss M, Bley TA, et al. Investigating the chemokine receptor 4 as potential theranostic target in adrenocortical cancer patients. Clin Nucl Med. (2017) 42:e2934. doi: 10.1097/RLU.0000000000001435

25. Vag T, Gerngross C, Herhaus P, Eiber M, Philipp-Abbrederis K, Graner FP, et al. First experience with chemokine receptor CXCR4-targeted PET imaging of patients with solid cancers. J Nucl Med. (2016) 57:7416. doi: 10.2967/jnumed.115.161034

26. Lapa C, Kircher S, Schirbel A, Rosenwald A, Kropf S, Pelzer T, et al. Targeting CXCR4 with [(68)Ga]Pentixafor: a suitable theranostic approach in pleural mesothelioma? Oncotarget. (2017) 8:96732-7. doi: 10.18632/oncotarget.18235

27. Martin R, Juttler S, Muller M, Wester HJ. Cationic eluate pretreatment for automated synthesis of [(6)(8)Ga]CPCR4.2. Nucl Med Biol. (2014) 41:849. doi: 10.1016/j.nucmedbio.2013.09.002

28. Kaemmerer D, Peter L, Lupp A, Schulz S, Sanger J, Baum RP, et al. Comparing of IRS and Her2 as immunohistochemical scoring schemes in gastroenteropancreatic neuroendocrine tumors. Int J Clin Exp Pathol. (2012) 5:187-94.

29. Remmele W, Stegner HE. [Recommendation for uniform definition of an immunoreactive score (IRS) for immunohistochemical estrogenreceptor detection (ER-ICA) in breast cancer tissue]. Pathologe. (1987) 8:138-40.

30. Tamamura H, Fujii N. The therapeutic potential of CXCR4 antagonists in the treatment of HIV infection, cancer metastasis and rheumatoid arthritis. Expert Opin Ther Targets. (2005) 9:1267-82. doi: 10.1517/14728222.9.6.1267

31. Burger JA, Peled A. CXCR4 antagonists: targeting the microenvironment in leukemia and other cancers. Leukemia. (2009) 23:43-52. doi: 10.1038/leu.2008.299

32. Pernas S, Martin M, Kaufman PA, Gil-Martin M, Gomez Pardo P, LopezTarruella S, et al. Balixafortide plus eribulin in HER2-negative metastatic breast cancer: a phase 1, single-arm, dose-escalation trial. Lancet Oncol. (2018) 19:812-24. doi: 10.1016/S1470-2045(18)30147-5

33. Buck AK, Stolzenburg A, Hänscheid H, Schirbel A, Lückerath K, Schottelius M, et al. Chemokine receptor - Directed imaging and therapy. Methods. (2017) 130:63-71. doi: 10.1016/j.ymeth.2017.09.002

34. Lapa C, Luckerath K, Kircher S, Hanscheid H, Grigoleit GU, Rosenwald A, et al. Potential influence of concomitant chemotherapy on CXCR4 expression in receptor directed endoradiotherapy. Br J Haematol. (2019) 184:4403. doi: 10.1111/bjh.15096

35. Lapa C, Luckerath K, Kleinlein I, Monoranu CM, Linsenmann $\mathrm{T}$, Kessler AF, et al. (68)Ga-Pentixafor-PET/CT for imaging of chemokine receptor 4 expression in glioblastoma. Theranostics. (2016) 6:428-34. doi: 10.7150/thno.13986

36. Staller P, Sulitkova J, Lisztwan J, Moch H, Oakeley EJ, Krek W. Chemokine receptor CXCR4 downregulated by von Hippel-Lindau tumour suppressor pVHL. Nature. (2003) 425:307-11. doi: 10.1038/nature01874

37. Scotton CJ, Wilson JL, Scott K, Stamp G, Wilbanks GD, Fricker S, et al. Multiple actions of the chemokine CXCL12 on epithelial tumor cells in human ovarian cancer. Cancer Res. (2002) 62:5930-8.

38. Kaemmerer D, Schindler R, Mussbach F, Dahmen U, AltendorfHofmann A, Dirsch O, et al. Somatostatin and CXCR4 chemokine receptor expression in hepatocellular and cholangiocellular carcinomas: tumor capillaries as promising targets. BMC Cancer. (2017) 17:896. doi: 10.1186/s12885-017-3911-3

39. Rosen JM, Jordan CT. The increasing complexity of the cancer stem cell paradigm. Science. (2009) 324:1670-3. doi: 10.1126/science.1171837

Conflict of Interest Statement: The authors declare that the research was conducted in the absence of any commercial or financial relationships that could be construed as a potential conflict of interest.

Copyright (C) 2019 Werner, Kircher, Higuchi, Kircher, Schirbel, Wester, Buck, Pomper, Rowe and Lapa. This is an open-access article distributed under the terms of the Creative Commons Attribution License (CC BY). The use, distribution or reproduction in other forums is permitted, provided the original author(s) and the copyright owner(s) are credited and that the original publication in this journal is cited, in accordance with accepted academic practice. No use, distribution or reproduction is permitted which does not comply with these terms. 